\title{
Sazonalidade no balanço de energia em áreas de cultivo de soja na Amazônia
}

\author{
Paulo Jorge de Oliveira Ponte de Souza $\left({ }^{1 *}\right)$; Aristides Ribeiro ( $\left.{ }^{2}\right)$; Edson José Paulino da Rocha $\left({ }^{3}\right)$ \\ José Renato Bouças Farias (4); Everaldo Barreiros de Souza ( $\left(^{3}\right)$ \\ (1) Universidade Federal Rural da Amazônia, Avenida Presidente Tancredo Neves, n. ${ }^{2}$ 2501, 66077-901, Belém (PA), Brasil. \\ (2) Universidade Federal de Viçosa, Departamento de Engenharia Agrícola, Viçosa (MG), Brasil. \\ (3) Universidade Federal do Pará, Faculdade de Meteorologia, Caixa Postal 479, 66075-110 Belém (PA), Brasil. \\ (4) Embrapa Soja, Laboratório de Ecofisiologia, Caixa Postal, 231, 86001-970 Londrina (PR), Brasil. \\ (*) Autor correspondente: paulo.jorge@ufra.edu.br
}

Recebido: 13/mar./2011; Aceito: 13/out./2012

\begin{abstract}
Resumo
Neste trabalho, avaliou-se o balanço de energia na cultura soja (Glycine max (L.) Merrill), variedade Tracajá, durante a safra e entressafra, em uma área de avanço de fronteira agrícola na Amazônia, por meio do método da razão de Bowen. Durante quase todo o ciclo da cultura, maior parte da energia foi consumida na forma de calor latente, principalmente durante as fases de florescimento e frutificação. Tal característica esteve relacionada à elevada condutância estomática foliar da soja e à disponibilidade de água na região. Próximo ao fim do ciclo ocorreu uma inversão na partição de energia entre os componentes H e LE, quando maior parte da energia foi usada no aquecimento do ar (79\% do saldo de radiação). Durante a entressafra observou-se a redução de 75\% no fluxo de calor latente e aumento considerável de 180\% no fluxo de calor sensível comparado ao encontrada durante o ciclo.
\end{abstract}

Palavras-chave: fronteira agrícola, razão de Bowen, partição de energia.

\section{Seasonal energy balance in areas of soybean cultivation in the Amazon}

Abstract

It was investigated the energy balance in a soybean crop (Glycine max (L.) Merrill) grown in areas of advance of agricultural border in the Amazon. The Bowen ratio technique was used to obtain energy balance components. During the most part of the crop growing season, most of the energy was consumed as latent heat, especially during the flowering and fruiting stages. Such characteristic was related to the high leaf stomatal conductance of soybean as well as to the water availability in the region. At the harvest there was an inversion in the energy partitioning, with more energy being used for heating the air (79\% of the net radiation). During the off-season there was 75\% reduction in the LE and significant increase in the $\mathrm{H}$ (180\%) compared to the values found during soybean growing season.

Key words: agricultural border, Bowen ratio, energy balance.

\section{INTRODUÇÃO}

O cultivo da Soja (Glycine max (L.) Merryl) na Amazônia teve inicio na década de 2000, ocupando inicialmente uma área total de 73 mil ha. No Estado do Pará, a área cultivada era de apenas 1.200 ha, mas a região vinha recebendo incentivos do governo desde 1994 para estimular o aumento da produção de grãos principalmente nas regióes de Santarém e Paragominas (Souza et al., 2008).

Em 2008, a área cultivada com soja no Estado chegou a $71 \mathrm{mil} \mathrm{ha,} \mathrm{com} \mathrm{produtividade} \mathrm{média} \mathrm{de} 3 \mathrm{t} \mathrm{ha}^{-1}$ (SAGRI, 2009). O crescimento da sojicultura no Pará se deveu a novas variedades menos sensíveis a elevadas temperaturas e principalmente ao fotoperiodo, possibilitando sua produção em regióes de baixa latitude (Sinclair et al., 2005). Soares-Filho et al. (2005) estimam que mais de $50 \%$ da área original da Amazônia seria ocupada com soja até 2030 , caso não haja uma ação firme do governo no combate ao desmatamento. Em eventuais circunstâncias, a soja poderia ser considerada um risco iminente para a biodiversidade e clima da Amazônia.

Apesar dos impactos decorrentes do avanço da soja na Amazônia (Souza et al., 2008), Vera-Diaz et al. (2008) verificaram que ao se excluir as áreas protegidas como terras indígenas e reservas florestais, apenas $20 \%$ da Amazônia legal (1,0 milhão km²) seria considerada área potencial para rendimentos da soja superiores a 2 t ha ${ }^{-1}$. No entanto, $44 \%$ de toda esta área citada 
pertence ao Estado do Mato Grosso, onde a expansão da área cultivada com soja está finalizada (MiragaYa, 2008), fato que inviabilizaria economicamente o contínuo avanço desta cultura na Amazônia pela necessidade de elevados investimentos para aumentar o potencial produtivo nas demais áreas.

A maioria dos trabalhos feitos sobre balanço de energia com a cultura da soja como os realizados por Fernandes (2007) em São Paulo; Fontana et al. (1991) no Rio Grande do Sul; SAUER et al. (2007) em Iowa e Suyker e Verma (2008) em Nebraska, Estados Unidos, descrevem uma variabilidade bem definida na partição da energia, com grande parte dessa energia sendo usada na forma de calor latente e um aumento no consumo de calor sensível durante o período que antecede a maturação.

Apesar de todos os resultados indicarem uma variabilidade semelhante para este tipo de cultura, a magnitude observada na partição de energia diferiu significativamente entre os diferentes trabalhos como consequência dos efeitos locais no controle das trocas energéticas além de fatores como o tamanho da área de estudo e os sensores utilizados com diferentes princípios de funcionamento e diferentes respostas.

A dinâmica existente na fisiologia da cultura e consequentemente nos processos de trocas energéticas entre o ecossistema da soja e a atmosfera local, normalmente, não são consideradas em modelos de circulação geral e de meso-escala que tentam reproduzir impactos decorrentes do uso da terra comprometendo a acurácia dos resultados simulados (Cohen et al., 2007). Diante da necessidade de se quantificar tais processos, torna-se importante estudar a variabilidade dos componentes energéticos neste tipo de ecossistema, uma vez que tais informaçôes possibilitaráo melhor entendimento de como o ciclo hidrológico e o balanço energético local/regional poderão ser afetados pela mudança no uso da terra na Amazônia.

A técnica da razão de Bowen tem sido amplamente utilizada para a obtenção dos componentes do balanço energético em diferentes tipos de cultura como trigo (Lee et al., 2000), uva (Pezzopane e Pedro Junior, 2003) e cana de açúcar (InMAN-BAmber e McGlinchey, 2003), pelo fato de ser um método indireto, simples e prático de estimativa dos fluxos entre vegetação e atmosfera. Considera-se, no entanto, certas condiçôes-limite associadas principalmente à exigência mínima de bordadura
(Stannard, 1997) e ao efeito de advecçáo (Lee et al., 2004; Gavilan e Berengena, 2006). Em resultados conseguidos por meio deste método, têm-se notado uma precisão razoável (subestimativa de 5\%), quando comparado a resultados com lisímetros sob condiçôes em que não exista o efeito advectivo (SILVA et al., 2005).

Este estudo surgiu para investigar este novo padrão de mudança no uso da terra na Amazônia e tem por objetivo quantificar e analisar o balanço de energia durante um ciclo de produção de soja na Regiấo Leste da Amazônia.

\section{MATERIAL E MÉTODOS}

O experimento foi desenvolvido durante a safra de 2007, no município de Paragominas, situado na Regiáo Nordeste do Estado do Pará. Esta regiāo foi escolhida pelo fato de ter havido grande expansão do cultivo da soja nos últimos anos. A área experimental com cultivo de soja foi de 200 ha (02059'08'S; 47019'57'O; $122 \mathrm{~m}$ ), semeada mecanicamente com a cultivar Tracajá (ciclo precoce), em fileiras espaçadas de $0,5 \mathrm{~m}$ e espaçamento entre plantas de $0,1 \mathrm{~m}$. A semeadura foi realizada em 23 de fevereiro e a colheita, em 21 de junho do mesmo ano.

Uma torre instrumentada de $3 \mathrm{~m}$ de altura foi montada no centro da área contendo vários sensores micrometeorológicos (Tabela 1). Todos os sensores foram ligados a um datalogger CR10X (Campbell Scientific, Inc.) e um multiplexador AM416 (Campbell Scientific, Inc.).

Uma das principais preocupaçóes ao se instalar um sistema para medir a razão de Bowen diz respeito à representatividade da área que se pretende estudar e ao nível em que os sensores devem ser colocados (STANNARD, 1997), a fim de que seja validada a suposição que é feita quando se considera a homogeneidade existente entre os coeficientes de transporte turbulento dentro da subcamada inercial formada logo acima da vegetação (GAVILAN e Berengena, 2007). Resultados de Cellier e Brunet (1992) demonstram que o método da razão de Bowen, diferente de outros métodos como o aerodinâmico, pode ser aplicado muito perto da copa, pois mesmo que os diferentes níveis de medidas estejam localizados tanto na subcamada de rugosidade como na subcamada inercial, qualquer efeito gerado na primeira camada afetará similarmente ambos os perfis de temperatura e umidade do ar.

Tabela 1. Lista de instrumentos, alturas e mediçóes da estação meteorológica automática instalada no experimento da soja

\begin{tabular}{lcc} 
Variável meteorológica & Instrumento usado, fabricante (modelo) & Nível (m) \\
Radiação global incidente & Piranômetros Kipp \& Zonen (CMP3) & 2,45 \\
Saldo de radiação & NR Lite (Campbell Sci.) & 2,45 \\
Temperatura do ar & Termo-higrômetro Vaisala (HMP45A), PT100 resistores & 0,5 e 2 \\
Umidade relativa do ar & Termo-higrômetros Vaisala (HMP45A), & 0,5 e 2 \\
Chuva & Pluviômetro TB4 & 3,9 \\
Umidade do solo & Reflectômetro de domínio do tempo - TDR & $0-0,30$ \\
Fluxo de calor no solo & Placa de fluxo Hukseflux (HFP01SC-L) & $-0,10--0,10$ \\
\hline
\end{tabular}


Outro detalhe importante é que na presença de advecção, a área-fonte torna-se diferentemente distribuída, inviabilizando a consideração de similaridade entre os dois coeficientes de transporte turbulento, havendo um efeito muito maior quando a área de interesse não possui bordadura suficiente (LeE et al., 2004). No entanto, de acordo com LaUbach et al. (2000), mesmo em condiçóes advectivas, a razão entre os coeficientes de difusão turbulenta para o calor sensível $\left(\mathrm{K}_{\mathrm{H}}\right)$ e para o vapor d'água $\left(\mathrm{K}_{\mathrm{LE}}\right)$ não é muito diferente de 1 e o método pode ser usado com limitados erros. Por esse motivo, os instrumentos foram instalados com suficiente bordadura na direção predominante do vento (de 900 a 1000 m) a fim de se evitar problemas associados ao efeito de áreas adjacentes nas medidas, obedecendo a razão sugerida de 1:100 (ROSEMBERG et al., 1983; Stannard, 1997). O nível dos sensores foi alterado frequentemente com o crescimento da cultura, mantendo-se sempre o mesmo intervalo do perfil vertical, de modo a garantir que eles permanecessem dentro da camada-limite de equilíbrio (Rosemberg et al., 1983).

A análise do desenvolvimento da soja foi feita diariamente usando a classificação dos estádios proposta por Fehr e Caviness (Farias et al., 2001) em um experimento inteiramente ao acaso, com quatro repetiçóes, onde as diferentes fases fenológicas são representadas pelos símbolos $\mathrm{V}$ para o período vegetativo e $\mathrm{R}$ para período reprodutivo, como a seguir: VE a emergência, Vn todo o período vegetativo, R1 a R2 a fase de florescimento, R3 a R4 o período de formação de vagem, R5 o início de enchimento de grãos, R6 o enchimento pleno e R7 a R8 o período de maturação da cultura. Dados para análise da área foliar foram coletados semanalmente a partir dos dez dias após a semeadura. As amostras consistiram de escolhas aleatórias de linhas de um metro de comprimento com seis repetições. A área foliar foi obtida por meio de coleta de 30 discos foliares por repetição e estimada de acordo com método proposto por Benincasa (2003). O índice de área foliar (IAF) foi entáo estimado considerando estas medidas e a massa seca das folhas amostradas.

Os componentes do balanço de energia analisados são representados pela Equação 1:

$R n=H+L E+G$

em que: $R n$ representa o saldo de radiação, $H, L E$ e $G$ os fluxos de calor sensível, latente e no solo, respectivamente, todos em $\mathrm{MJ} \mathrm{m}^{-2}$.

A energia armazenada no dossel foi desconsiderada no balanço por apresentar relativa importância apenas durante as fases de transição do dia (Moore e Fisch, 1986), representando no caso da soja no máximo $8 \%$ do saldo de radiação no início do dia (Meyers e Hollinger, 2004). A energia transportada lateralmente foi também desprezada pela condição de extensa bordadura imposta no experimento (Gavilan e Berengena, 2007).
Os componentes $\mathrm{H}$ e LE foram obtidos a partir da razão de Bowen ( $\beta$ ) medida através das relações do transporte vertical de calor sensível e vapor d'água, assumindo a igualdade nos coeficientes de transporte turbulento $\left(\mathrm{K}_{\mathrm{H}}\right.$ e $\mathrm{K}_{\mathrm{LE}}$ ) (Perez et al., 1999).

$$
\begin{aligned}
& \beta=\frac{H}{L E}=\frac{C p}{\lambda} \frac{\Delta T}{\Delta q}=\gamma \frac{\Delta T}{\Delta e} \\
& L E=\frac{R n-G}{1+\beta}
\end{aligned}
$$

em que: $\lambda$ é o calor latente de evaporação $\left(\mathrm{J} \mathrm{kg}^{-1}\right)$, Cp o calor específico do ar $\left(1013 \mathrm{~J} \mathrm{~kg}^{-1} \mathrm{C}^{-1}\right), q$ a umidade específica, $\gamma=\frac{C_{p} \cdot P}{0,622 . \lambda}$ o coeficiente psicrométrico $\left(\mathrm{Kpa}^{\circ} \mathrm{C}^{-1}\right), \mathrm{P}$ a pressão atmosférica (hPa), $\Delta \mathrm{T}$ e $\Delta$ e são ambos a diferença da temperatura do ar e da pressão de vapor d'água entre dois níveis consecutivos respectivamente.

Diferentes critérios são utilizados para a eliminação de dados não confiáveis deste método, como valores de $\beta$ iguais a -1 , ou valores de $\beta$ menores que -0.75 (OrtegAFarias et al., 1996). Adotou-se o método proposto por Perez et al. (1999) para a análise da consistência dos dados gerados pela razão de Bowen, em função dos sinais observados na relação fluxo-gradiente entre os componentes e de quais valores de $\beta$ próximos de -1 poderiam ser desprezados, com base na precisão das medidas de temperatura e umidade do ar, as quais foram consideradas, para o tipo de sensor usado, como $\pm 0,2{ }^{\circ} \mathrm{C}$ e $\pm 2 \%$ para a temperatura $(\delta \Delta \mathrm{T})$ e umidade relativa do ar $(\delta \Delta \mathrm{e})$ respectivamente. Tais valores foram utilizados para a obtenção do erro $(\varepsilon)$, a fim de se determinar o intervalo próximo de -1 a ser excluído. Assim, ao invés de considerar valores fixos, o intervalo de valores de $\beta$ a ser excluído dependerá do gradiente de pressáo de vapor medido e da resolução dos sensores, conforme equaçáo abaixo:

$$
\varepsilon=\left(\frac{\delta \Delta e-\gamma \delta \Delta T}{\Delta e}\right)
$$

Sendo o intervalo a ser excluído para valores de $\beta$ próximos de -1:

$-1-|\varepsilon|<\beta<-1+|\varepsilon|$

Após o controle de qualidade, utilizou-se critério semelhante ao adotado por Teixeira e BastiaAseen (2012) para o preenchimento de falhas, onde os dados de fluxo de energia ( $\mathrm{H}$ ou LE) eram obtidos em função da correlação encontrada com a energia disponível $(R n+G)$ para cada fase. Os horários mais comuns de ocorrência de erros pelo método da razão de Bowen são os referentes ao período noturno, ao amanhecer e no fim da tarde, estes dois últimos decorrentes da mudança no sinal nos saldos de radiação e no fluxo de calor no solo (Perez et al., 1999; Silva et al., 2007; Teixeira e BastiaAseen, 2012) 
O déficit de pressão de vapor foi calculado pela diferença entre a pressão de saturação de vapor d'água obtida pela equação de Tetens e a pressão atual de vapor d'água obtida a partir da umidade relativa.

\section{RESULTADOS E DISCUSSÃO}

\section{Período de crescimento}

Durante todo o ciclo da soja, o saldo de radiaçáo $(\mathrm{Rn})$ atingiu valores máximos próximos de $600 \mathrm{~W} \mathrm{~m}^{-2} \mathrm{em}$ torno do meio-dia (Figura 1). À medida que a soja cresceu, ocorreu um aumento considerável no fluxo de calor latente logo após a formação do $50^{\circ}$ trifoliolado (V5) até a fase de enchimento de grãos (R5), onde se verificou picos de LE de 503, 440, 444 e $468 \mathrm{~W} \mathrm{~m}^{-2}$ nas fases V5-Vn, R1-R2, R3-R4 e R5 respectivamente. Como consequência, menor quantidade de energia foi utilizada para o fluxo de calor sensível, que resulta no aquecimento do ar e do solo. O aumento no consumo da energia pela evapotranspiração durante este período está diretamente associado ao aumento no índice de área foliar (FARIAS et al., 2001) e à ocorrência de baixa resistência do dossel ao transporte de vapor d'água devido às boas condiçôes de disponibilidade de água (Ortega-Farias et al., 2004). O total de chuvas durante todo o ciclo foi de $410 \mathrm{~mm}$ (Tabela 2), valor próximo da exigência mínima da soja (FARIAS et al., 2007), com maior disponibilidade até a fase de enchimento de grãos, o que também contribuiu para o maior consumo de energia na forma de calor latente durante estas fases.

Durante quase todo o estádio reprodutivo da soja (R1-R6), pouca energia atingiu a superfície do solo devido aos elevados valores de IAF. Enquanto o solo estava parcialmente coberto, observaram-se picos instantâneos de até $48 \mathrm{~W} \mathrm{~m}^{-2}$ de energia de fluxo de calor no solo, o que corresponde a valores de G/Rn de aproximadamente 0,10 . À medida que ocorreu o fechamento do dossel, a irradiância que atingiu o solo diminuiu com picos máximos de $8 \mathrm{~W} \mathrm{~m}^{-2}$ de fluxo de calor no solo $(\mathrm{G} / \mathrm{Rn}=0,03)$.

Durante o período de cobertura plena, pouca energia foi utilizada na forma de calor sensível. Porém, após a fase de vagem cheia (R6) houve aumento considerável neste componente (Figura 1). A partir desta fase, ocorreu uma expressiva redução em LE devido à senescência das folhas em decorrência da translocação de nitrogênio e de biomassa para os grãos (Sinclair et al., 2005). Como consequência deste processo, houve considerável redução na área foliar da soja, a qual se tornou um importante fator, juntamente com a redução no total de chuvas, os quais controlaram a partiçáo da energia, conforme constatado por Suyker e Verma (2008), que encontraram valores de evapotranspiração da soja da ordem de 1 a $2 \mathrm{~mm} \mathrm{dia}^{-1}$ causada pela senescência de folhas.

Durante o período inicial de fechamento incompleto do dossel, a evapotranspiração média encontrada por Souza et al. (2011) para o mesmo experimento foi de $3,7 \mathrm{~mm}$ por dia, sugerindo que durante esta fase (IAF $<1$ ) poderia estar havendo contribuição significativa da evaporaçáo na perda de água pela superfície em função da elevada disponibilidade de água proveniente das chuvas. Resultados de Sakuratani (1987) indicam que a transpiração na soja chega a representar mais que $50 \%$ do processo, mesmo com IAF próximo de 1, particularmente em casos com diminuiçáo no conteúdo de água do solo, onde a evaporação é rapidamente afetada. SAUER et al. (2007) encontraram transpiração da soja de $3,2 \mathrm{~mm}$, a qual representou $65 \%$ da evapotranspiraçáo medida quando o IAF era de 1,86. Estes resultados indicam que a reduçáo no consumo de energia na forma de LE observada durante a fase final do ciclo, ocorreu principalmente em consequência da redução da disponibilidade de água. Entretanto, haveria a necessidade de outro experimento em que se pudesse controlar a disponibilidade de água durante esta fase para comprovar esta hipótese.

Durante o estádio de maturaçáo plena (R7-R8), quando a vagem estava praticamente seca, houve inversão nos componentes do balanço de energia, passando a existir maior aquecimento do ar (H) (Tabela 2). A diminuição do total de chuvas durante esta fase (Figura 2) foi decisiva na partição da energia próximo da maturação, fazendo com que a energia fosse consumida preferencialmente no aquecimento do ar.

Entretanto, ressalta-se que nesta fase final do ciclo, com a redução das chuvas, a área pode ter sofrido efeito

Tabela 2. Média diária dos componentes do balanço de energia e partição durante 24 horas em diferentes fases da soja na Amazônia

\begin{tabular}{|c|c|c|c|c|c|c|c|c|}
\hline \multirow[t]{2}{*}{ Fases } & \multirow[t]{2}{*}{ IAF } & \multirow{2}{*}{$\begin{array}{l}\text { Chuva } \\
(\mathrm{mm})\end{array}$} & \multicolumn{4}{|c|}{ 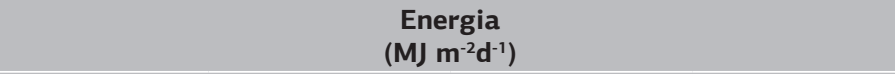 } & \multicolumn{2}{|c|}{ Partição de energia } \\
\hline & & & $\mathbf{R n}$ & G & LE & $\mathbf{H}$ & LE/Rn & H/Rn \\
\hline P-V1 & 0,04 & 32,8 & $12,10( \pm 0,97)$ & $-0,01( \pm 0,10)$ & $8,01( \pm 0,58)$ & $3,88( \pm 0,46)$ & 0,66 & 0,32 \\
\hline V1-V5 & 0,45 & 91,0 & $11,46( \pm 0,61)$ & $-0,17( \pm 0,04)$ & $9,38( \pm 0,45)$ & $2,24( \pm 0,20)$ & 0,82 & 0,20 \\
\hline V5-R1 & 1,56 & 60,4 & $11,39( \pm 0,82)$ & $-0,12( \pm 0,03)$ & $9,51( \pm 0,65)$ & $1,97( \pm 0,18)$ & 0,83 & 0,17 \\
\hline $\mathrm{R} 1-\mathrm{R} 2$ & 3,63 & 36,0 & $11,06( \pm 0,82)$ & $-0,14( \pm 0,03)$ & $9,15( \pm 0,68)$ & $2,00( \pm 0,19)$ & 0,83 & 0,18 \\
\hline R3-R4 & 3,81 & 105,2 & $10,97( \pm 0,47)$ & $-0,14( \pm 0,03)$ & $8,85( \pm 0,42)$ & $2,22( \pm 0,20)$ & 0,81 & 0,20 \\
\hline R5 & 3,98 & 43,8 & $11,69( \pm 0,47)$ & $-0,07( \pm 0,02)$ & $9,63( \pm 0,42)$ & $2,12( \pm 0,17)$ & 0,82 & 0,18 \\
\hline R6 & 2,99 & 17,8 & $11,13( \pm 0,39)$ & $-0,07( \pm 0,03)$ & $7,48( \pm 0,44)$ & $3,70( \pm 0,39)$ & 0,67 & 0,33 \\
\hline R7-R8 & 0,20 & 23,4 & $11,45( \pm 0,27)$ & $-0,02( \pm 0,02)$ & $2,41( \pm 0,60)$ & $9,05( \pm 0,60)$ & 0,21 & 0,79 \\
\hline
\end{tabular}




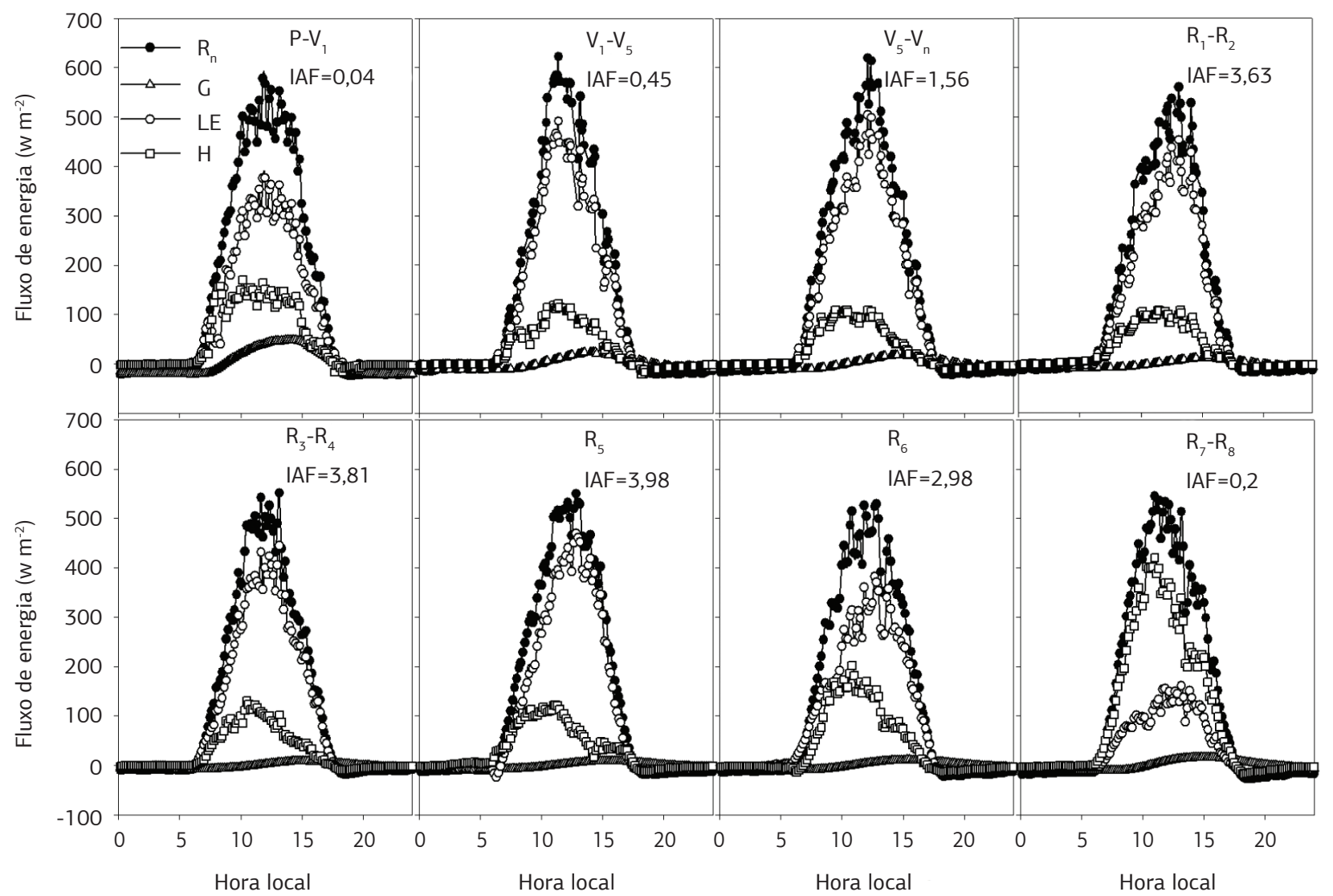

Figura 1. Ciclo diário médio dos componentes do balanço de energia para cada fase fenológica da soja. IAF é o valor médio do Índice de área foliar observado na fase. Rnet $(\bullet)$ = saldo de radiação, LE $(\circ)$ = fluxo de calor latente, $\mathrm{H}(\square)$ = fluxo de calor sensível e G $(\Delta)=$ fluxo de calor no solo.

de advecção da área ao redor, inviabilizando a consideração de similaridade entre os dois coeficientes de transporte turbulento, e indicado certo cuidado na interpretaçáo destes resultados durante este período. Nestas condiçôes, há um efeito muito maior quando a área de interesse não possui bordadura suficiente (LeE et al., 2004), embora não seja este o caso, pois na área de estudo existe bordadura entre 900 e 1000 m na direção predominante do vento. A possível ocorrência de advecção lateral nesta fase pode ser devida ao tamanho da área utilizada neste trabalho, a qual por ter uma extensão considerável (200 ha), não necessariamente estaria sob o mesmo regime de chuvas observado no local de medição, que pela própria climatologia da região é comum a formaçáo de chuvas convectivas e localizadas (De Souza e Rocha, 2006). Por outro lado, de acordo com LaUbach et al. (2000), mesmo em condiçóes advectivas, a razão entre os coeficientes de difusão turbulenta para o calor sensível $\left(\mathrm{K}_{\mathrm{H}}\right)$ e para o vapor d'água $\left(\mathrm{K}_{\mathrm{LE}}\right)$ náo é muito diferente de 1 e o método pode ser usado com limitados erros.

O maior consumo de energia no processo de evapotranspiraçáo ocorreu durante o estádio reprodutivo, com consumo médio diário de $83 \%$ de Rn (Tabela 2). Fontana et al. (1991) obtiveram consumo médio diurno de aproximadamente $95 \%$ da energia na forma de calor latente para a soja irrigada no Rio Grande do Sul, e de $78 \%$ sem irrigação. Estes resultados diferem um pouco dos encontrados neste trabalho pelo fato de aqueles autores realizarem o estudo em uma regiáo diferente, adotando diferentes condiçôes de manejo e distintas condiçôes climáticas comparadas aos deste experimento.

$\mathrm{Na}$ maturação fisiológica, maior parte da energia foi usada no aquecimento do ar (80\%), uma vez que com o processo de senescência das folhas, a soja reduziu consideravelmente sua taxa de transpiração, permanecendo basicamente a evaporação da água do solo, somada com a dessecação do material ainda existente que também contribuiu no computo de LE (SAUer et al., 2007). Aliado a isto, a redução das chuvas também contribuiu para a inversão na partição da energia, sendo o principal fator no controle desta partição.

Os baixos valores de LE no início do dia estão associados à formação de nevoeiro na regiáo, o qual foi observado todos os dias (Figura 3). Apesar de existir um consumo instantâneo de mais de $80 \%$ da energia na evapotranspiração entre as fases V1 e R5 durante o período diurno, quando o saldo de radiação é positivo, grande parte deste consumo ocorre somente após o meio dia local (Figura 3). 


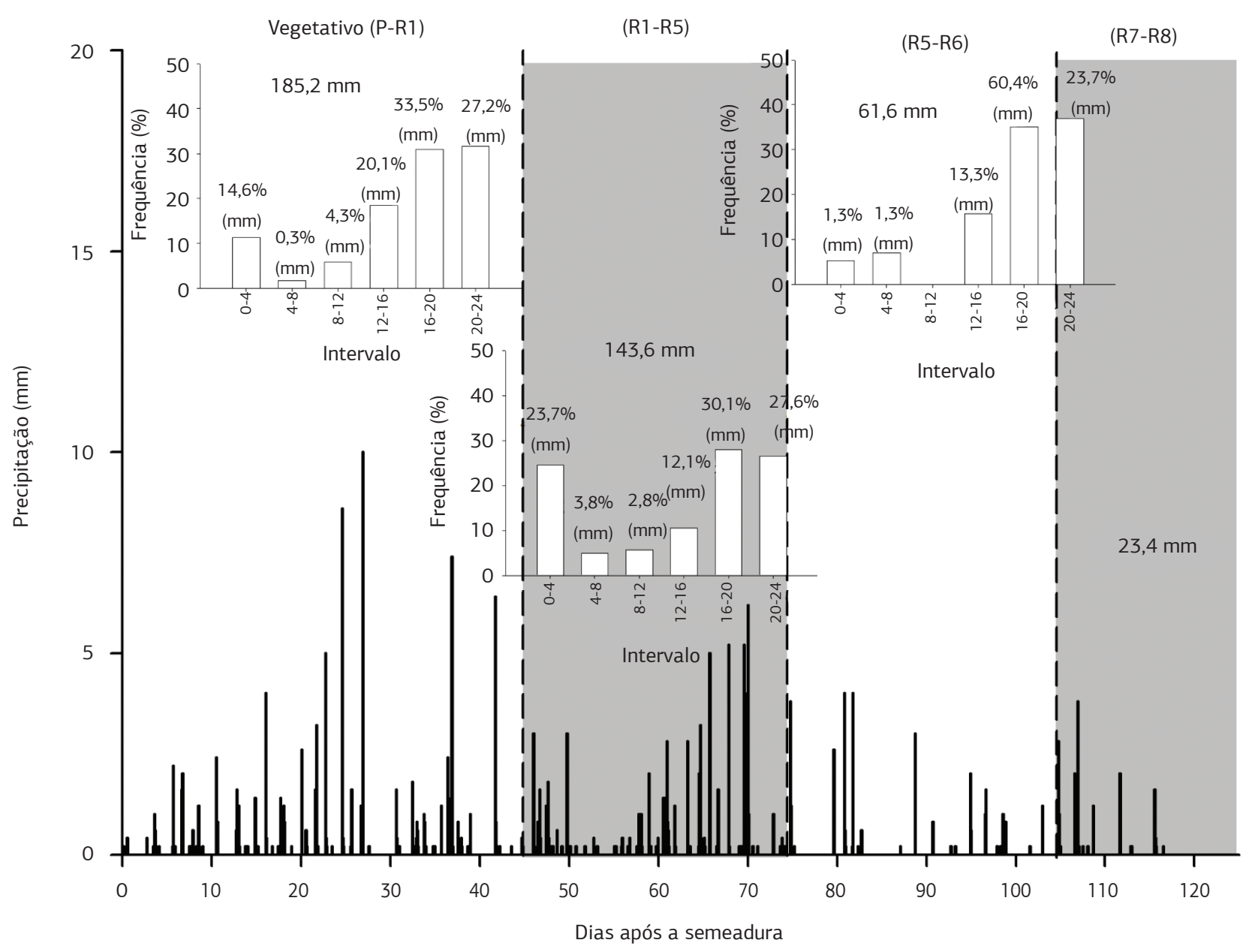

Figura 2. Evoluçáo temporal do regime pluviométrico durante o ciclo cultural da soja na Amazônia em 2007. Figuras internas representam a frequência de ocorrência de todos os eventos de chuva nos três principais períodos em função do intervalo do dia com respectivas fraçóes do total de chuva no período.

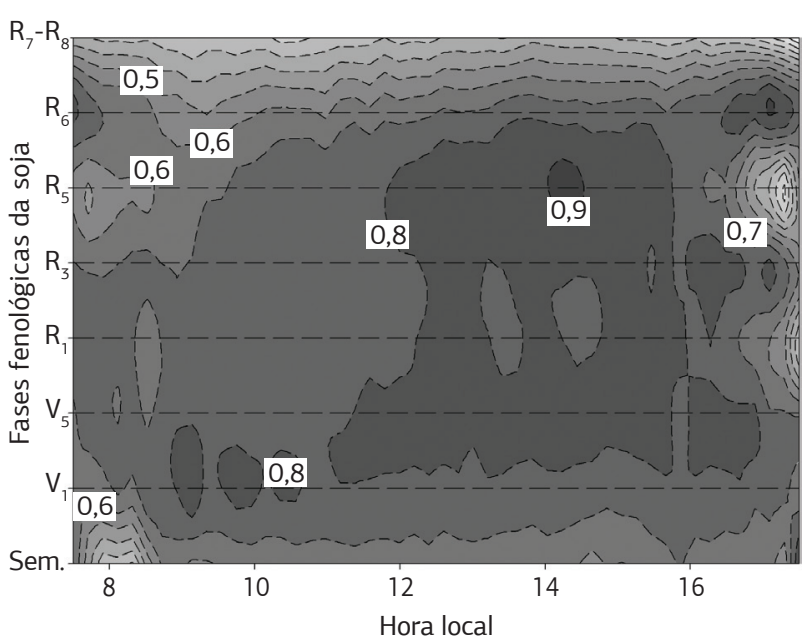

Figura 3. Consumo médio horário do saldo de energia na forma de calor latente durante período diurno ao longo do ciclo da soja.

Pela parte da tarde ocorre um consumo de quase toda a energia entre V1 e R5 (80-90\%) devido à grande disponibilidade de água e energia. Esta variaçâo horária no consumo da energia pela soja ocorreu pelo fato de nesta regiâo, as chuvas terem ocorrido com maior frequência a partir do meio dia (Figura 2), aumentando a disponibilidade de água no solo neste horário, além do maior déficit de pressáo de vapor existente entre as 11 e 16 horas.

Os componentes do balanço de energia e o déficit de pressão de vapor d'água em um dia considerado seco, após quatro dias sem chuva, e em um dia chuvoso após três dias consecutivos de ocorrência de chuva durante a máxima cobertura do dossel e o máximo consumo de energia pela evapotranspiração são apresentados na figura 4. Nestes dois dias, o consumo médio de energia pela evapotranspiração no período diurno não foi muito diferente, independente da ocorrência ou não de chuvas (Figura 3c-d). No dia considerado úmido (82 DAS), a energia consumida pela evapotranspiração $(\mathrm{Rn}-\mathrm{G}>0)$ correspondeu a $74 \%$ $\left(10,5 \mathrm{MJ} \mathrm{m}^{-2}\right)$ da energia disponível, enquanto o aquecimento do ar consumiu 26\% (3,6 $\left.\mathrm{MJ} \mathrm{m}^{-2}\right)$. Com a ausência de chuvas durante um período de quatro dias seguidos, a partiçáo da energia durante cobertura completa do dossel correspondeu a $72 \%\left(8,9 \mathrm{MJ} \mathrm{m}^{-2}\right)$ para LE e $28 \%$ (2,6 $\left.\mathrm{MJ} \mathrm{m}^{-2}\right)$ para $\mathrm{H}$ (79 DAS).

A importância das variáveis meteorológicas apresentadas na figura 4 pode ser justificada pela frequente ocorrência de chuvas convectivas na região, em elevada 


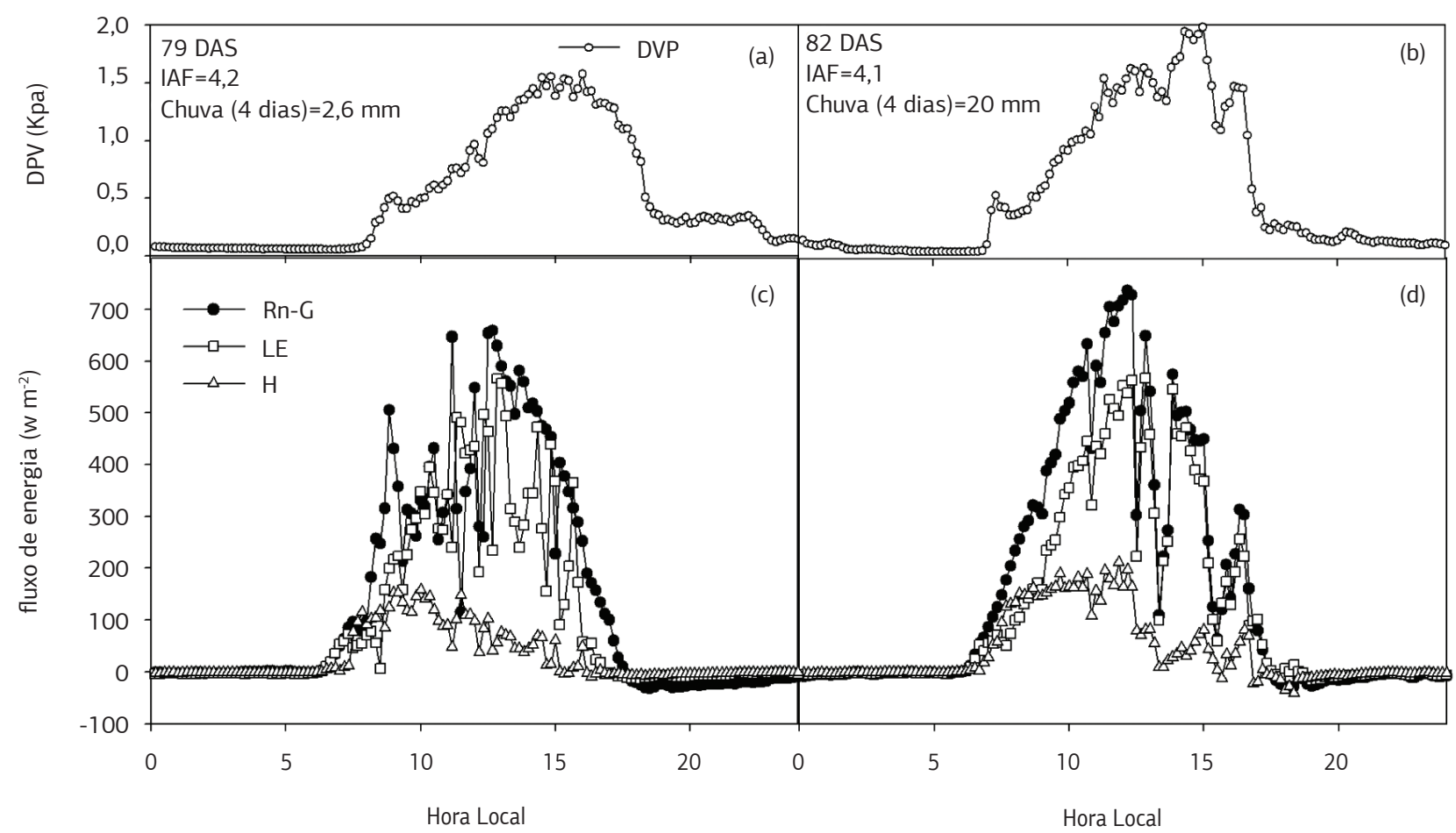

Figura 4. Déficit de pressão de vapor (DPV) e componentes do balanço de energia (Rn-G, LE, H), durante um dia seco (a,c) e um dia úmido (b,d) na fase R5 da soja.

quantidade, o que mantém o armazenamento de água no solo em níveis adequados por vários dias seguidos sem alterar a taxa evapotranspirativa. Considera-se o período em que ainda há a ocorrência das chuvas, diferente do que ocorre no fim do ciclo cultural, quando há reduçáo nas chuvas, corroborando a importância da elevada disponibilidade de água existente neste processo.

$\mathrm{Na}$ figura 5, observa-se a variabilidade que ocorreu no consumo da água do solo durante toda a fase de enchimento de grãos. Nota-se que a ausência de chuvas por si só não chega a afetar o balanço energético, como visto na figura 4, pelo fato de existir água disponível no solo, fazendo com que o processo seja controlado pela disponibilidade de energia. Resultados similares foram obtidos por SAKAI et al. (2004) para o cultivo de arroz na Região Amazônica, onde a evapotranspiração foi controlada apenas pela forçante radiativa, uma vez que não houve restrição de água para a cultura. Resultados obtidos por SuIKeR e Verma (2008) sugerem um limite no IAF da soja entre 3 e 4, a partir do qual a evapotranspiração deixa de sofrer efeito direto da cobertura foliar, explicado pelo fato de não haver aumento relativo na interceptação da radiaçấo.

Em todo o experimento o IAF não ultrapassou 4,1, o que demonstra a importância secundária da cobertura foliar no controle da evapotranspiração nesta região, justificada pela elevada umidade da superfície do solo, especialmente nos períodos com baixos valores de IAF. Tais resultados sugerem que o elevado consumo de energia na evapotranspiração durante maior parte do ciclo está associado às condiçôes climáticas locais as quais a cultura ficou exposta, desempenhando um importante papel no

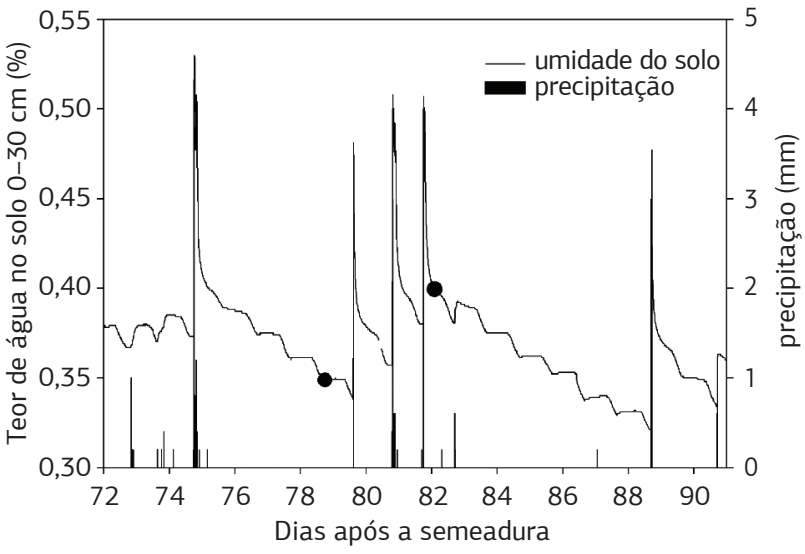

Figura 5. Evolução temporal do consumo de água do solo durante a fase de enchimento de grãos da soja na Amazônia em 2007.

controle do processo de transferência de vapor d'água ao longo do ciclo. Logo, no período de semeadura da soja na Amazônia que coincide com a maior disponibilidade de água, o aumento no IAF complementa a maior utilização de energia na evapotranspiração da soja.

\section{Período de Entressafra}

Os componentes $\mathrm{H}$ e LE tiveram uma variação sazonal bastante brusca durante todo o sistema de produção da soja na região (Figura 6). Durante o ciclo da soja, que dura cerca de $1 / 3$ do ano, maior parte da energia foi consumida pelo calor latente, e pouca energia foi direcionada para $\mathrm{H}$ (Tabela 3). Um fato interessante, no entanto, foi a 
ocorrência de brusca alteração no balanço de energia após o período da colheita, que se estendeu por cerca de $2 / 3$ do ano. Esta variação sazonal na partiçấo de energia tem efeito direto no ciclo hidrológico pelo fato de existir uma significativa redução na evapotranspiração durante a entressafra. Tal variabilidade é semelhante ao encontrado por SAKAI et al. (2004) para diferentes formas de uso da terra na Amazônia. O mesmo foi constatado por SuIKER e Verma (2008) em sistemas de rotação de milho e soja nos Estados Unidos.

Nota-se uma rápida mudança na partição de energia a partir do início da senescência, seguindo o declínio do IAF e a diminuição da disponibilidade hídrica. Até a fase $\mathrm{R} 6$, os valores médios diurnos da razão LE/Rn tiveram uma variação típica de 0,5 a 0,95 e os de $\mathrm{H} / \mathrm{Rn}$ entre 0,1 e 0,3 . Após a senescência, os valores da partição para LE decresceram para valores entre 0,1 e 0,2 e para $\mathrm{H}$ aumentaram para o intervalo entre 0,8 e 0,9 mantendo esta variabilidade durante todo o período de entressafra, como consequência da menor disponibilidade hídrica.
Após a colheita da soja nesta região da Amazônia ocorreu uma redução de $75 \%$ no fluxo de calor latente e um aumento significativo (180\%) no fluxo de calor sensível, além de exposiçáo direta do solo, ocasionando um aumento no fluxo do calor em profundidade (Tabela 3). Esta brusca mudança ocorreu efetivamente pela redução no regime de chuvas que é comum nesta época do ano na região e pela redução na cobertura foliar. Esta mudança na partição de energia e consequente reduçáo na fraçáo de calor latente é uma das principais consequências das atividades agrícolas nos ecossistemas terrestres, devido à diminuiçáo no período de crescimento das culturas e cobertura do solo (CHEN et al., 2009) e da redução do sistema radicular destes tipos de coberturas vegetais, o qual causa expressiva diminuição na evapotranspiraçáo, por exemplo, em ecossistemas de pastagem na Amazônia (Von Randow et al., 2011).

SAUER et al. (2007) observaram variabilidade semelhante na partição da energia durante a transição ciclo/

Tabela 3. Componentes do balanço de energia médio durante o ciclo e entressafra da soja na Amazônia

\begin{tabular}{|c|c|c|c|c|}
\hline \multirow{2}{*}{ Período } & Rnet & H & LE & G \\
\hline & $\left(\mathrm{MJ} \mathrm{m}^{-2} \mathrm{~d}^{-1}\right)$ & (MJ $m^{-2} d^{-1}$ ) & (MJ $m^{-2} d^{-1}$ ) & (MJ $m^{-2} d^{-1}$ ) \\
\hline Ciclo & $11,57( \pm 0,20)$ & $3,33( \pm 0,23)$ & $8,23( \pm 0,26)$ & $-0,08( \pm 0,01)$ \\
\hline Entressafra & $11,66( \pm 0,17)$ & $9,32( \pm 0,14)$ & $2,06( \pm 0,06)$ & $0,28( \pm 0,02)$ \\
\hline (\%) & $+0,8$ & $+179,88$ & $-74,97$ & 450 \\
\hline
\end{tabular}

Valores em parênteses representam erro-padrăo de estimativa.

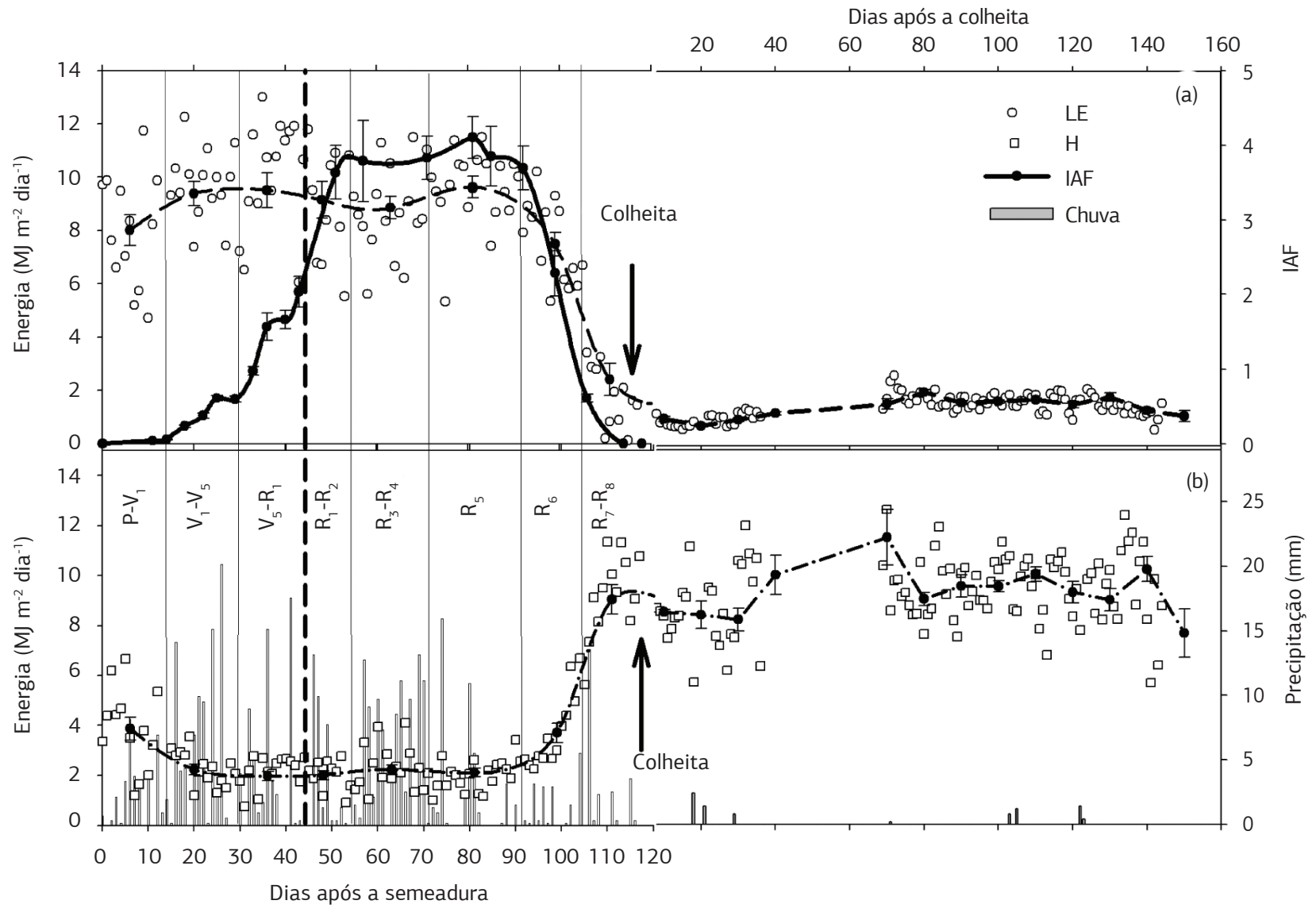

Figura 6. Variabilidade sazonal dos componentes do balanço de energia ao longo do período de produção da soja na Amazônia. 
entressafra da soja nos Estados Unidos, havendo, porém, diferentes magnitudes do observado neste estudo. É importante observar também que, nesta regiấo, logo após a colheita o solo é deixado em repouso com restos culturais e com vegetação rasteira em crescimento, sendo um dos principais motivos da grande mudança encontrada na entressafra, uma vez que há importante reduçáo no volume de solo a ser explorado como também pela diminuiçáo da umidade do solo em consequência da diminuição das chuvas (Figura 6b). Esta variação sazonal nos componentes do balanço de energia é comumente desconsiderada em estudos de modelagem climática e sua inclusão pode vir a ser um dos fatores para melhorar a eficácia dos mesmos, especialmente em estudos sobre impactos pela mudança do uso da terra na Amazônia. Pelos resultados encontrados por Souza et al. (2008), avalia-se que o avanço da soja na região Amazônica causa alteraçóes importantes no albedo da superfície, alterando o balanço de radiação local quando da substituição de áreas de floresta.

\section{CONCLUSÃO}

Durante o ciclo da soja ocorre uma transição gradual na partiçâo de energia entre os componentes com mais energia sendo usada como calor latente, especialmente entre as fases de florescimento e enchimento de grãos, em função de sua elevada condutância do dossel. Observou-se um importante controle da forçante radiativa e uma importância secundária do índice de área foliar na partição da energia ao longo do ciclo.

Durante a fase inicial, pequena parte da irradiância é direcionada para o solo, havendo brusca redução após o fechamento do dossel. Maior parte da energia é direcionada para a evapotranspiração, havendo redução no fluxo de calor latente próximo da maturação, devido ao redirecionamento da energia para a componente $\mathrm{H}$. Há variação sazonal significativa nas componentes do balanço de energia ao longo do sistema de produçáo da soja na Amazônia. Durante o período da entressafra, há considerável aumento no fluxo de calor sensível e brusca redução no fluxo de calor latente devido ao sistema de produção empregado na regiấo.

\section{REFERÊNCIAS}

BENINCASA, M. P. Análise de crescimento de plantas (noções básicas). Jaboticabal: Funep, 2003. 41p.

CELLIER, P.; BRUNET, Y. Flux-gradient relationships above tall plant canopies. Agricultural and Forest Meteorology, v.58, p.93-117, 1992.

CHEN, S.; CHEN, J.; LIN, G.; ZHANG, W.; MIAO, H.; WEI, L.; HUANG, J.; HAN, X. Energy balance and partition in
Inner Mongolia steppe ecosystems with different land use types. Agricultural and Forest Meteorology, v.29, p.1800-1809, 2009.

COHEN, J.C.P.; BELTRÃO, J.C.; GANDU, A.W.; SILVA, R.R. Influência do desmatamento sobre o ciclo hidrológico da Amazônia. Ciência e Cultura, v.59, p.36-39, 2007.

DE SOUZA, E.B.; ROCHA, E.J.P. Diurnal Variability of rainfall in Bragança-PA (Eastern Amazon) during rainy season: Mean characteristics and extreme events. Revista Brasileira de Meteorologia, v.21, p.142-152, 2006.

FARIAS, J.R.B.; ASSAD, E.D.; ALMEIDA, I.R.; EVANGELISTA, B.A.; LAZZAROTO, C.; NEUMAIER, N.; NEPOMUCENO, A.L. Caracterização de risco de défict hídrico nas regiôes produtoras de soja no Brasil. Revista Brasileira de Agrometeorologia, v.9, p.415-421, 2001.

FARIAS, J. R. B.; NEPOMUCENO, A. L.; NEUMAIER, N. Ecofisiologia da soja. Londrina: Embrapa Soja, 2007. 9p. (Circular técnica, 48)

FERNANDES, E.J. Estudo do calor sensível e latente obtidos por intermédio da razão de Bowen em uma cultura de soja irrigada. Irriga, v.12, p.281-296, 2007.

FONTANA, D. C.; BERLATO, M.A.; BERGAMASHI, H. Balanço de energia em soja irrigada e não irrigada. Pesquisa Agropecuária Brasileira, v.26, p.403-410, 1991.

GAVILAN, P.; BERENGENA, J. Accuracy of the Bowen ratioenergy balance method for measuring latent heat flux in a semiarid advective environment. Irrigation Science, v.25, p.127-140, 2007.

INMAN-BAMBER, N. G.; MCGLINCHEY, M. G. Crop coefficients and water-use estimates for sugarcane based on longterm Bowen ratio energy balance measurements. Field Crops Research, v.83, p.125-138, 2003.

LAUBACH, J.; MCNAUGHTON, K.G.; WILSON, J.D. Heat and water vapour diffusivities near the base of a disturbed stable internal boundary layer. Boundary Layer Meteorology, v.94, p.23-63, 2000.

LEE, X.; YU, Q.; SUN, X.; LIU, J.; MIN, Q.; LIU, Y.; ZHANG, $\mathrm{X}$. Micrometeorological fluxes under the influence of regional and local advection: a revisit. Agricultural and Forest Meteorology, v.122, p.111-124, 2004.

MEYERS, T.P.; HOLLINGER, S.R. An assessment of storage terms in the surface energy balance of maize and soybean. Agricultural and Forest Meteorology, v.125, p.105-115, 2004.

MIRAGAYA, J. Demanda mundial de carne bovina tem provocado o desmatamento na Amazônia. T\&C Amazônia, n.14, p.35-45, 2008.

MOORE, C.J., FISCH, G. Estimating heat storage in Amazonian Tropical Forest. Agricultutal and Forest Meteorology, v.38, p.147169, 1986.

ORTEGA-FARIAS, S.O.; CUENCA, R.H.; EK, M. Daytime variation of sensible heat flux estimated by the bulk aerodynamic method over a grass canopy. Agricultural and Forest Meteorology, v.81, p.131-143, 1996. 
ORTEGA-FARIAS, S.O.; OLIOSO, A.; ANTONIOLETTI, R.; BRISSON, N. Evaluation of the Penman-Monteith model for estimating soybean evapotranspiration. Irrigation Science, v.23, p.1-9, 2004.

PEZZOPANE, J.R.M.; PEDRO JR, M.J. Balanço de energia em vinhedo de "Niagara Rosada". Bragantia, v.62, p.155-161, 2003.

PEREZ, P.J.; CASTELLVI, F; IBAÑEZ, M.; ROSELL, J.I. Assessment of reliability of Bowen ratio method for partitioning fluxes. Agricultural and Forest Meteorology, v.97, p.141-150, 1999.

ROSEMBERG, N.J.; BLAD, B.L.; VERMA, S.B. Microclimate: the biological environment. 2.ed. New York: John Wiley, 1983. 495p.

SAKURATANI, T. Separate estimation of transpiration and evaporation from soybean field without water shortage. Journal of Agricultural Meteorology, v.42, p.309-317, 1987.

SAKAI, R.K.; FITZJARRALD, D.R.; MORAES, O.L.L.; STAEBLER, R.M.; ACEVEDO, O.C.; CZIKOWSKY, M.J.; SILVA, R.; BRAIT, E.; MIRANDA, V. Land-use change effects on local energy, water, and carbon balances in an Amazonian agricultural Field. Global Change Biology, v.10, p.895-907, 2004.

SAUER, T.J.; SINGER, J.W.; PRUEGER, J.H.; DESUTTER, T.M.; HATFILED, J.L. Radiation balance and evaporation partitioning in a narrow-row soybean canopy. Agricultural and Forest Meteorology, v.145, p.206-214, 2007.

SECRETARIA DE AGRICULTURA DO ESTADO DO PARÁ. Evolução da produção no estado do Pará por município de 1994 a 2008. Disponível em: <www.sagri.pa.gov.br>. Acesso em 12/5/2009.

SILVA, L.D.B.; FOLEGATTI, M.V., VILLA NOVA, N.A. Evapotranspiraçáo do capim tanzânia obtida pelo método de razão de Bowen e lisímetro de pesagem. Engenharia Agrícola, v.25, p.705-712, 2005.

SILVA, T.J.A.; FOLEGATTI, M.V., SILVA, C.R.; ALVES JUNIOR, J.; SILVA, E.M.B. Balanço de energia e estimativa da evapotranspiração em culturas irrigadas de maracujazeiro pelo método da razão de Bowen. Engenharia Agrícola, v.27, p.392-403, 2007.
SINCLAIR, T R ; NEUMAIER, N. ; FARIAS, J. R. B. ; NEPOMUCENO, A L. Comparison of vegetative development in soybean cultivars for low-latitude environmets. Field Crops Research, v.92, p.53-59, 2005.

SOARES-FILHO, B.S.; NEPSTAD, D.C.; CURRAN, L.; CERQUEIRA, G.; GARCIA, R.A.; RAMOS, C.A.; LEFEBVRE, P.; SCHLESINGER, P.; VOLL, E.; MCGRATH, D. Cenários de desmatamento para Amazônia. Estudos Avançados, v.19, p.138$152,2005$.

SOUZA, P.J.O.P.; FARIAS, J.R.B.; MELO E ABREU, J.P.M.; RIBEIRO, A.; ROCHA, E.J.P.; BOTELHO, M.N.; SOUSA, A.M.L. Simulation of soybean growth and yield under northeastern Amazon climatic conditions. Pesquisa Agropecuária Brasileira, v. 46, p. 567-577, 2011.

SOUZA, P.J.O.P.; ROCHA, E.J.P.; RIBERO, A.; LOUREIRO, R.S.; BISPO, C.J.C. Impactos no albedo em conseqüência do avanço da fronteira agrícola na Amazônia. Revista Brasileira de Agrometeorologia, v.16, p.87-95, 2008.

SUYKER, A.E.; VERMA, S.B. Interannual water vapor and energy exchange in an irrigated maize-based agroecosystem. Agricultural and Forest Meteorology, v.148, p.417-427, 2008.

STANNARD, D.I. A theoretically based determination of bowenratio fetch requirements. Boundary Layer Meteorology, v.83, p.375-406, 1997.

TEIXEIRA, A.H.C.; BASTIAANSSEN, W.G.M. Five methods to interpret field measurements of energy fluxes over a micro-splinkerirrigated mango orchard. Irrigation Science, v.30, p.13-28, 2012.

VERA-DIAZ, M. DEL C.; KAUFMANN, R.K.; NEPSTAD, D.C.; SCHLESINGER, P. An interdisciplinary model of soybean yield in the Amazon Basin: The climatic, edaphic, and economic determinants. Ecological Economics, v.65, p.420-431, 2008.

VON RANDOW, R.C.S.; VON RANDOW, C.; HUTJES, R.W.A.; TOMASELLA, J.; KRUIJT, B. Evapotranspiration of deforested areas in central and southwestern Amazonia. Theoretical and Applied Climatology, v.109, p.205-220, 2011. 